\title{
Explaining socioeconomic inequalities in illicit drug use disorders in Iran
}

\author{
Maryam Karimian ${ }^{1 *}$, Abbas Motevalian $^{1}$, Maryam Damghanian ${ }^{2}$, Afarin Rahimi-Movaghar ${ }^{3}$, \\ Vandad Sharifi ${ }^{4}$, Masoumeh Amin-Esmaeili ${ }^{5}$, Ahmad Hajebi ${ }^{6}$
}

Received: 16 Mar 2017 Published: 18 Dec 2017

\begin{abstract}
Background: Drug use disorders are one of the major health problems in societies, which cause physical, psychological, and social damages to individuals. Socioeconomic status is often inversely associated with drug use disorders. The present study aimed at determining the effect of socioeconomic inequality on the prevalence of drug use disorders and identifying its determinants in Iran.

Methods: Data of 7886 individuals aged 15 to 64 years were collected from Iran Mental Health Survey (IranMHS). Initially, the socioeconomic status of the participants was determined by principal component analysis. Later, socioeconomic inequality was measured using the concentration index, and the factors influencing the gap between the high and low socioeconomic groups were identified using the Oaxaca-Blinder Decomposition.

Results: The concentration index for drug use disorders in Iran was -0.29 (standard error $=0.06$ ). The results of decomposition technique revealed that $1.14 \%$ and $2.7 \%$ of the participants with high and low socioeconomic status were affected by drug use disorders, respectively. In addition, the gap between these 2 groups was found to be $1.65 \%$. Among the studied variables, occupation, marital status, and gender accounted for the highest contribution to inequality, respectively.

Conclusion: There is inequality in the prevalence of drug use disorders in Iran; these disorders are more common in lower socioeconomic group. Based on the findings, it is suggested that improvement in the socioeconomic status of the households, especially for males, the divorced or widowed individuals, and the unemployed may lead to a reduction in inequality in drug use disorders.
\end{abstract}

Keywords: Drug use disorders, Socioeconomic inequality, Oaxaca-Blinder Decomposition

Copyright $\odot$ Iran University of Medical Sciences

Cite this article as: Karimian M, Motevalian A, Damghanian M, Rahimi-Movaghar A, Sharifi V, Amin-Esmaeili M, Hajebi A. Explaining socioeconomic inequalities in illicit drug use disorders in Iran. Med J Islam Repub Iran. 2017 (18 Dec);31:108. https://doi.org/10.14196/mjiri.31.108

\section{Introduction}

Drug abuse or dependence is followed by extensive outcomes in public health (1). Drug abusers experience higher rates of suicide attempts (2-3) and disability (4) than others in the general population. The simultaneous incidence of drug use disorders and mental disorders is very common (5), as such these people suffer from poor health, unemployment, and housing instability (6-10), and they usually do not receive appropriate care and treatment services (11). Another consequence of drug abuse is the

Corresponding author: Maryam Karimian, smkarimian89@gmail.com

1. Department of Epidemiology, School of Public Health, Iran University of Medical Sciences, Tehran, Iran.

2. Nursing and Midwifery Care Research Center, Tehran University of Medical Sciences, Tehran, Iran.

3. Iranian National Center for Addiction Studies (INCAS), Tehran University of Medical Sciences, Tehran, Iran.

4. Psychiatry and Psychology Research Center and department of Psychiatry, Tehran University of Medical Sciences, Tehran, Iran.

5. Department for Mental Health and Substance Use, Iranian Research Center for HIV/AIDS (IRCHA), Tehran University of Medical Sciences, Tehran, Iran.

6. Research Center for Addiction and Risky Behaviors (ReCARB), Psychiatric Department, Iran University of Medical Sciences, Tehran, Iran. heavy costs imposed on societies. For example, the annual cost related to drug use in the US is estimated to be 181 billion dollars $(12,13)$.

There is a growing interest in the study of the relationship between socioeconomic status and drug use. However, there are conflicting pieces of evidence on this relationship, as some studies have reported a positive relationship and others a negative relationship between them. For instance, some indicators of high socioeconomic status

$\uparrow$ What is "already known" in this topic:

When inequalities in the health sector are measured, a natural approach is to search to explain them. The core idea is to explain the distribution of the outcome variable by a set of factors. The Oaxaca decomposition outlined in this study is one of the methods capable of explaining inequalities.

\section{$\rightarrow$ What this article adds:}

When faced with a gap in outcome variable between the 2 groups, researchers frequently try to determine how much of the gap can be explained by differences in observable characteristics. In addition to this part, the Oaxaca decomposition can specify the difference in the coefficients. This trait is exclusive to the Oaxaca method. 
such as higher educational attainment of parents or higher family income have been shown to be associated with drug use $(14,15)$, while higher educational attainment of individuals has been reported to be related to reduced drug use (16). Antony (1971) found that academic achievement has a positive and negative relationship with cannabis and cocaine use, respectively (17).

Inequality in health is a kind of difference in the health status of individuals based on which vulnerable social groups or those who permanently experience adverse conditions and discrimination are exposed to more risk factors than other social groups (18). To the best of our knowledge, no studies have been conducted on determining the effect of socioeconomic inequality on the prevalence of drug use disorders using the decomposition techniques. Most studies have merely dealt with the relationship between socioeconomic status and drug use disorder without evaluating the contribution of the variables to this relationship (19-21). A study was conducted in Iran in 2011 entitled "Iran Mental Health Survey (IranMHS)", and one of its objectives was to determine the prevalence of any drug use disorder (drug abuse and dependence) in the past 12 months $(22,23)$. Therefore, based on the data obtained from IranMHS, the present study aimed at determining the rate of socioeconomic inequality in the prevalence of drug use disorders and identifying the factors causing the gap between groups with low and high socioeconomic status in Iran. The results could be helpful in the identification of subgroups of the population, who are more susceptible to drug use.

\section{Methods}

The data of Iran Mental Health Survey (IranMHS) were used in the present study. In this study, 7886 individuals aged 15 to 64 years were selected using a three-stage random sampling method. The required data were collected through a demographics questionnaire, socioeconomic status, and Composite International Diagnosis Interview Version 2.1 (CIDI 2.1). CIDI 2.1 was used to diagnose mental disorders in the past 12 months. The drug use part of this scale consists of items about screening, the frequency of use, and symptoms of disorders (drug use and dependence). The drugs studied in this questionnaire include cannabis, stimulants, opiates, cocaine, hallucinogens, and inhalants (22).

Principal component analysis (PCA) was done based on the data of household assets including personal home, villa or garden, independent kitchen, bathroom, toilet, color TV or LCD, refrigerator, freezer, mobile phone, washing machine, dishwasher, microwave, vacuum cleaner, computer, internet connection, and motorbike and car for personal use. The first component of the analysis, which explained more of the variance, was set as the indicator of socioeconomic status (24).

The rate of inequality in drug use disorders was measured using the concentration index, which is calculated based on the concentration curve and is equal to twice the area between the concentration curve and line of equality (25). The horizontal and vertical axes of this curve represent the socioeconomic status as the cumulative percent- age from the poorest to the richest and health as the cumulative percentage. If health has more accumulation among the poor, the concentration curve lies above the line of equality and the concentration index would be negative. By contrast, if health has more accumulation among the rich, the concentration curve lies below the line of equality and the concentration index would be positive. If the line of equality and concentration curve is the same, the concentration index would be 0 , indicating equality. This index ranges between -1 and +1 . Using Equation 1, concentration index can be easily calculated based on the covariance between the health status and fractional rank in the distribution of socioeconomic status $C=\frac{2}{\mu}\left(h_{i} r_{i}\right)$; where $h_{i}$ is the health status of individual $i, \mu$ is its mean, $r_{i}$ is the fractional rank of individual $i$ in the distribution of the SES variable, and cov denotes the covariance $(26,27)$.

The impact of independent variables (age group, gender, marital status, education, and occupation, place of residence, income, and socioeconomic status) on the outcome variable (any drug use disorder) was measured using simple and multiple logistic regression.

Based on the median of socioeconomic status, the participants were assigned into 2 groups of high $(n=3872)$ and low socioeconomic status $(n=3801)$. Then, the rate of inequality in the prevalence of drug use disorders and the contribution of effective factors to the gap between the 2 groups were determined using the Oaxaca-Blinder Decomposition (OBD). Generally, OBD method decomposes the mean difference of the outcome variable into 2 parts: one part is due to group differences in the determinants of the outcome variable (sometimes called the explained component or endowments) and another part is due to group differences in the effects of these determinants or differences in the coefficients, sometimes called the unexplained component or coefficients (25). ADePT Version 6 was used in to measure the concentration index and draw the concentration curve. Other statistical analyses were performed in STATA Version 13 at a significance level of 0.05 .

\section{Results}

Table 1 demonstrates the demographic characteristics of the participants and the prevalence of any drug use disorder, based on the study variables. Frequencies were weighted and estimated using a complex sample analysis. According to the results of IranMHS, the prevalence of any drug use disorder during the last 12 months was equal to $2.1 \%$.

Concentration index for drug use disorders in Iran was 0.29 (standard error $=0.06$ ). The negative sign of concentration index and its curve, which lies above the line of equality (Fig. 1), indicate the higher concentration of these disorders in participants with low socioeconomic status. Table 2 demonstrates the relationship between demographic characteristics of the sample and the 12-month prevalence of drug use disorders. Based on the results of simple logistic regression, gender, the 30-39 age group, education, marital status, occupation, income, and socioeconomic status had a significant relationship with drug 
Table 1. Sociodemographic characteristics and 12-month prevalence of any drug use disorder in the IranMHS (N=7886), Iran, 2011

\begin{tabular}{|c|c|c|c|}
\hline \multirow[t]{2}{*}{ Characteristics } & \multirow[t]{2}{*}{ N (Weighted \%) } & \multicolumn{2}{|c|}{ Any drug use disorder } \\
\hline & & $\mathrm{N}$ & $\%(95 \% \mathrm{CI})$ \\
\hline \multicolumn{4}{|l|}{ Age groups (years) } \\
\hline $15-19$ & $999(18.1)$ & 9 & $1.2(0.5,1.9)$ \\
\hline $20-29$ & $2550(33.8)$ & 41 & $1.9(1.4,2.4)$ \\
\hline $30-39$ & $2199(21.8)$ & 62 & $3.0(2.3,3.8)$ \\
\hline $40-49$ & $1189(15.3)$ & 30 & $2.7(1.7,3.6)$ \\
\hline $50-59$ & $702(8.7)$ & 7 & $1.4(0.5,2.3)$ \\
\hline $60-64$ & $247(2.5)$ & 2 & $1.4(-0.1,2.9)$ \\
\hline \multicolumn{4}{|l|}{ Gender } \\
\hline Female & 4499 (49.5) & 15 & $0.3(0.2,0.5))$ \\
\hline Male & $3387(50.5)$ & 136 & $3.8(3.1,4.4)$ \\
\hline \multicolumn{4}{|l|}{ Marital Status } \\
\hline Never married or Married & $7552(96.4)$ & 139 & $2.0(1.7,2.3)$ \\
\hline Previously married ${ }^{\text {a }}$ & $332(3.6)$ & 12 & $4.3(2.1,6.5)$ \\
\hline \multicolumn{4}{|l|}{ Education } \\
\hline University & $1208(18.5)$ & 10 & $0.9(0.4,1.5)$ \\
\hline Diploma or less & $6666(81.5)$ & 141 & $2.3(1.9,2.7)$ \\
\hline \multicolumn{4}{|l|}{ Occupation } \\
\hline Non-unemployed & $7147(90.5)$ & 110 & $1.7(1.4,2.0)$ \\
\hline Unemployed & $737(9.5)$ & 41 & $5.5(3.9,7.2)$ \\
\hline \multicolumn{4}{|l|}{ Residence } \\
\hline Rural & $3506(29.1)$ & 76 & $2.3(1.8,2.8)$ \\
\hline Urban & $4380(70.9)$ & 75 & $1.9(1.6,2.4)$ \\
\hline \multicolumn{4}{|l|}{ Income (per month) } \\
\hline More than $2,000,000$ Rials (189 USD) & $5462(75.5)$ & 81 & $1.7(1.3,2.0)$ \\
\hline Less than $2,000,000$ Rials (189 USD) & $2355(24.5)$ & 67 & $3.1(2.4,3.8)$ \\
\hline \multicolumn{4}{|l|}{ Socioeconomic status } \\
\hline High & $3872(58.3)$ & 44 & $1.2(0.8,1.6)$ \\
\hline Low & $3801(41.7)$ & 106 & $3.4(2.8,3.9)$ \\
\hline
\end{tabular}

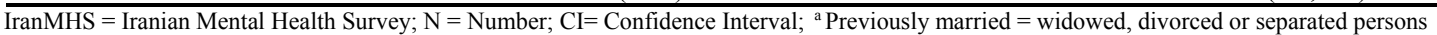

Table 2. Sociodemographic correlates of 12-month prevalence of any drug use disorder in the IranMHS (N=7886), Iran, 2011

\begin{tabular}{|c|c|c|c|c|}
\hline \multirow[t]{2}{*}{ Characteristics } & \multicolumn{4}{|c|}{ Any drug use disorder } \\
\hline & Unadjusted $\mathrm{OR}^{\mathrm{b}}(95 \% \mathrm{CI})$ & $\mathrm{p}$ & Adjusted $\mathrm{OR}^{\mathrm{c}}(95 \% \mathrm{CI})$ & $\mathrm{p}$ \\
\hline \multicolumn{5}{|l|}{ Age groups (years) } \\
\hline $15-19$ & 1 & - & 1 & - \\
\hline $20-29$ & $1.6(0.7,3.6)$ & 0.247 & $1.5(0.7,3.6)$ & 0.263 \\
\hline $30-39$ & $2.6(1.2-5.8)$ & 0.019 & $2.4(1.1-5.4)$ & 0.034 \\
\hline $40-49$ & $2.3(0.9-5.3)$ & 0.058 & $2.1(0.9-4.8)$ & 0.101 \\
\hline $50-59$ & $1.2(0.4-3.6)$ & 0.757 & $1.1(0.4-3.5)$ & 0.836 \\
\hline $60-64$ & $1.2(0.2-6.1)$ & 0.806 & $1.0(0.2-5.3)$ & 0.994 \\
\hline \multicolumn{5}{|l|}{ Gender } \\
\hline Female & 1 & - & 1 & - \\
\hline Male & $11.4(5.9-21.8)$ & $<0.001$ & $12.5(6.4-24.5)$ & $<0.001$ \\
\hline \multicolumn{5}{|l|}{ Marital Status } \\
\hline Never married or Married & 1 & - & 1 & - \\
\hline Previously married ${ }^{\mathrm{a}}$ & $2.2(1.1-4.5)$ & 0.028 & $4.2(1.9-8.9)$ & $<0.001$ \\
\hline \multicolumn{5}{|l|}{ Education } \\
\hline University & 1 & - & 1 & - \\
\hline Diploma or less & $2.5(1.2-5.2)$ & 0.018 & $2.0(0.9-4.2)$ & 0.092 \\
\hline \multicolumn{5}{|l|}{ Occupation } \\
\hline Non-unemployed & 1 & - & 1 & - \\
\hline Unemployed & $3.3(2.1-5.1)$ & $<0.001$ & $1.7(1.1-2.8)$ & 0.026 \\
\hline \multicolumn{5}{|l|}{ Residence } \\
\hline Rural & 1 & - & 1 & - \\
\hline Urban & $0.8(0.6-1.2)$ & 0.396 & $1.2(0.9-2.0)$ & 0.177 \\
\hline \multicolumn{5}{|l|}{ Income (per month) } \\
\hline More than $2,000,000$ Rials (189 USD) & 1 & - & 1 & - \\
\hline Less than $2,000,000$ Rials (189 USD) & $1.8(1.3-2.8)$ & 0.002 & $1.2(0.7-1.9)$ & 0.483 \\
\hline \multicolumn{5}{|l|}{ Socioeconomic status } \\
\hline High & 1 & - & 1 & - \\
\hline Low & $2.8(1.8-4.2)$ & 0.002 & $2.4(1.4-3.9)$ & $<0.001$ \\
\hline
\end{tabular}

use disorders $(\mathrm{p}<0.05)$. In addition, the results of multiple logistic regression revealed that the risk of drug use disorders during the past 12 months was significantly higher in males than in females $(\mathrm{p}<0.01)$ in the $30-39$ age group than in other age groups $(\mathrm{p}=0.034)$, in divorced or widowed individuals than in single or married ones $(\mathrm{p}<0.001)$, in unemployed individuals than in employed ones $(\mathrm{p}=0.026)$, and in people with low socioeconomic status than in those with high socioeconomic status $(p<0.001)$. Because there were no significant differences in education, place of residence, and income, these variables were excluded from the final multiple model and others were 


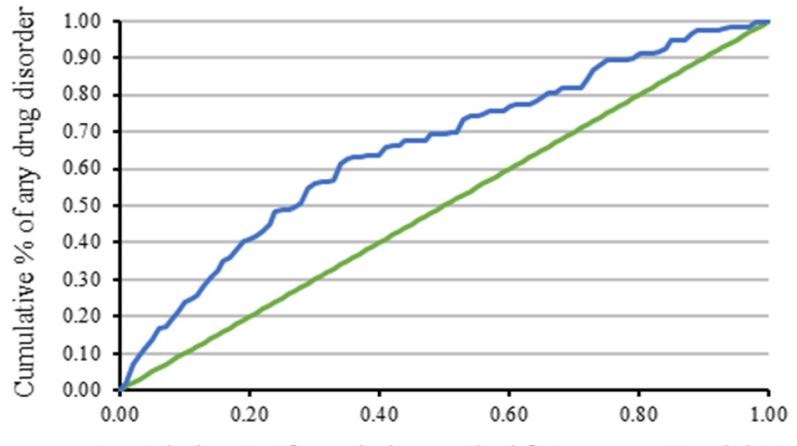

Cumulative $\%$ of population, ranked from poorest to richest

Line of equality

Any drug use disorder

Fig. 1. Concentration curve of any drug use disorder in Iran

Table 3. Differences in the prevalence of any drug use disorder between low and high socioeconomic groups, Iran, 2011

\begin{tabular}{llc}
\hline Any drug use disorder & $\%(95 \% \mathrm{CI})$ & $\mathrm{p}$ \\
\hline Prevalence in high socioeconomic group & $1.14(0.80,1.47)$ & $<0.001$ \\
Prevalence in low socioeconomic group & $2.79(2.26,3.31)$ & $<0.001$ \\
Differences & $-1.65(-2.27,-1.03)$ & $<0.001$ \\
Amount attributable to endowments (explained) & & 0.011 \\
Gender & $0.11(0.02,0.19)$ & 0.562 \\
Age group (years) & $-0.01(-0.03,0.02)$ & 0.012 \\
Marital Status & $-0.07(-0.13,-0.02)$ & $<0.001$ \\
Occupation & $-0.18(-0.27,-0.07)$ & 0.045 \\
Total & $-0.15(-0.29,-0.01)$ & $<0.001$ \\
Amount attributable to coefficients (unexplained) & & 0.025 \\
Gender & $-1.25(-1.85,-0.65)$ & 0.030 \\
Age group (years) & $-0.49(-0.92,-0.06)$ & 0.561 \\
Marital Status & $-0.15(-0.29,-0.01)$ & 0.134 \\
Occupation & $-0.08(-0.35,0.19)$ & $<0.001$ \\
Constant & $0.47(-0.14,1.10)$ & $-1.50(-2.10,-0.91)$ \\
Total & & \\
\hline
\end{tabular}

$\mathrm{CI}=$ confidence interval

entered into the OBD model.

Table 3 demonstrates the results obtained from the OBD method. The rate of the gap between the 2 groups in the prevalence of drug use disorders was $1.65 \%$, which was in favor of participants with high socioeconomic status. The contributions of explained and unexplained components were 0.15 and 1.5 , respectively. In unexplained component, it was observed that gender, marital status, and the 30-39 age group accounted for a significant proportion of the difference between the 2 groups $(\mathrm{p}<0.05)$. In this part, (a) Differences in the prevalence of any drug use disorder

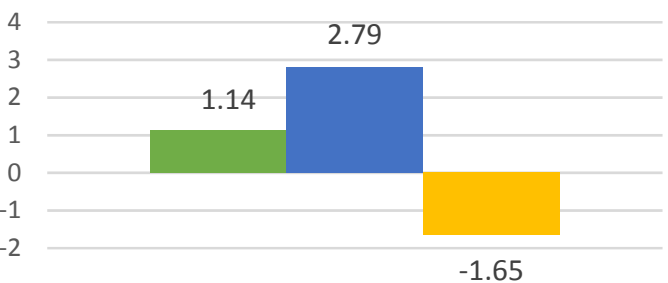

- Prevalence in high socioeconomic group

- Prevalence in low socioeconomic group

Differences (b) Decomposition of differences in the prevalence of any drug use disorder

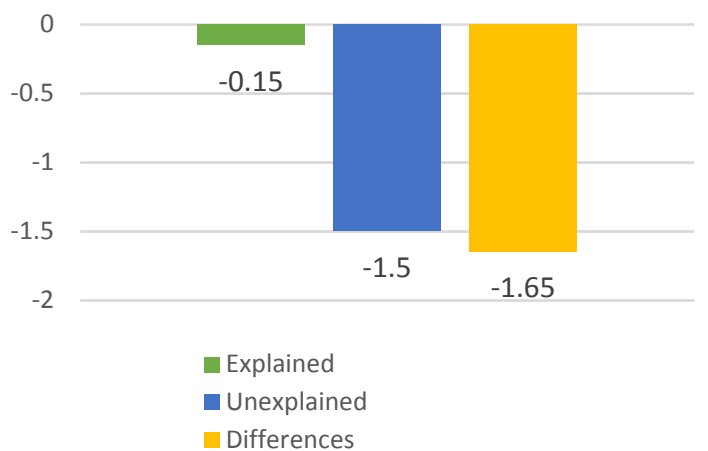

Fig. 2. Oaxaca-Blinder Decomposition 
intercept was positive, which was in favor of the participants with low socioeconomic status although it was not statistically significant $(p=0.134)$. A schematic view of the difference between the 2 groups in the prevalence of drug use disorders (2a) and decomposition of this difference into explained and unexplained components using OBD method (2b) are depicted in Fig. 2.

\section{Discussion}

In the present study, the prevalence of drug use disorders in the group with low socioeconomic status was 2.44 times more than that of the group with high socioeconomic status, suggesting the considerable role of socioeconomic factors in these disorders. The results obtained from measuring inequality using the concentration index and decomposition by OBD method revealed that inequality distribution in drug use disorders is in favor of high socioeconomic group in Iran. If these 2 groups are considered equal in the study variables, only $9.1 \%$ ( 0.15 out of 1.65$)$ of the difference between them can be eliminated, and the remaining $90.9 \%$ ( 1.50 out of 1.66$)$ can be attributed to the unexplained component. Because a significant proportion of the gap between the 2 groups is related to the unexplained component, there may be other factors affecting this inequality that are still unknown.

The most important factors affecting the inequality between the 2 groups in explained component, in order of priority, include occupation (-0.18), marital status (-0.07), and gender (0.11). However, the 30-39 age group is not statistically significant as an effective factor in the gap $(\mathrm{p}=0.562)$.

To the best of our knowledge, no studies have been conducted on determining the effect of socioeconomic inequality on the prevalence of drug use disorders using the decomposition techniques. However, inequality has been studied in some psychiatric disorders (28-31).

Although it is generally accepted that socioeconomic status is associated with drug use disorders, there is no consensus yet on the quality of this relationship (32-33). Similar to a study conducted in the US in 2004, the results of logistic regression in the present study revealed that the prevalence of drug use and dependence disorders in males is higher than in females (19). In another study in the US, it was found that unemployment is associated with increased prevalence of drug abuse or dependence (20-21). In the present study, drug use disorders during the past 12 months were higher among the unemployed than the employed. The results of linear and logistic regression models in a study conducted by Charitonidi et al. (2016) indicated that increased income level and educational attainment of households increases the risk of alcohol abuse, while low family income and educational attainment increases the risk of smoking (34). The results of a longitudinal study revealed that accessibility to educational facilities is associated with reduced risk of drug use disorders (35). According to the present study and another study by Karriker-Jaffe (2013), the risk of cigarette and marijuana use is higher among people living in deprived areas with low socioeconomic status (36).

The use of IranMHS data was one of the strengths of this study because this national survey had features such as large sample size, precise design of the sampling method to avoid selection bias, high rate of response, quality control protocol, monitoring of fieldwork, and the use of CIDI 2.1 as a diagnostic instrument, which made it possible to compare the results of this study with other studies in the field of world mental health survey. One of the limitations of the present study was the participants' socioeconomic status being measured based on household asset data because in developing countries such as Iran, there is no standard of living to be used for people to classify the society into different groups of socioeconomic status. Another limitation of this study was its cross-sectional nature and the relationships observed between variables, which were not necessarily causal.

\section{Conclusion}

Generally, the unequal distribution of drug use disorders in Iran is in favor of the high socioeconomic group. In this study, unemployment was the most important factor affecting the prevalence of drug use disorders, and other parameters such as widowhood and gender (male) were also found to be influential in this inequality. To minimize inequalities in the prevalence of drug use disorders in Iran, policymakers in the health sector should deal with the identified factors through making an accurate evaluation and developing appropriate strategies. In addition, the unexplained component, which plays a significant role, should be taken into account in future studies to identify the unknown factors affecting drug use disorders.

\section{Conflict of Interests}

The authors declare that they have no competing interests.

\section{References}

1. McRae AL, Brady KT, Sonne SC. Alcohol and substance abuse. Med Clin North Am. 2001 May 1;85(3):779-801.

2. Borges G, Walters EE, Kessler RC. Associations of substance use, abuse, and dependence with subsequent suicidal behavior. Am J Epidemiol. 2000 Apr 15;151(8):781-9.

3. Dhossche DM, Meloukheia AM, Chakravorty S. The association of suicide attempts and comorbid depression and substance abuse in psychiatric consultation patients. Gen Hosp Psychiatry. 2000 Aug 31;22(4):281-8.

4. Murray CJ, Lopez AD. Alternative projections of mortality and disability by cause 1990-2020: Global Burden of Disease Study. The Lancet. 1997 May 24;349(9064):1498-504.

5. Mericle AA, Park VM, Holck P, Arria AM. Prevalence, patterns, and correlates of co-occurring substance use and mental disorders in the United States: variations by race/ethnicity. Compr Psychiatry. 2012 Aug 31;53(6):657-65.

6. Dickey B, Normand SL, Weiss RD, Drake RE, Azeni H. Medical morbidity, mental illness, and substance use disorders. Psychiatr Serv. $2002 \mathrm{Jul} ; 53(7): 861-7$.

7. Osher FC, Goldberg RW, McNary SW, Swartz MS, Essock SM, Butterfield MI, Rosenberg SD. Blood-borne infections and persons with mental illness: substance abuse and the transmission of hepatitis C among persons with severe mental illness. Psychiatr Serv. 2003 Jun;54(6):8427.

8. Watkins KE, Burnam A, Kung FY, Paddock S. A national survey of care for persons with co-occurring mental and substance use disorders. Psychiatr Serv. 2001 Aug;52(8):1062-8.

9. Watkins KE, Hunter SB, Wenzel SL, Tu W, Paddock SM, Griffin A, Ebener P. Prevalence and characteristics of clients with co-occurring 
disorders in outpatient substance abuse treatment. Am J Drug Alcohol Abuse. 2004 Jan 1;30(4):749-64.

10. McNiel DE, Binder RL. Psychiatric emergency service use and homelessness, mental disorder, and violence. Psychiatr Serv. 2005 Jun;56(6):699-704.

11. McFarland BH, Gabriel RM. Datapoints: service availability for persons with co-occurring conditions. Psychiatr Serv. 2004 Sep; 55(9):978-.

12. Harwood HJ, Bouchery E. The economic costs of drug abuse in the United States, 1992-2002. Executive Office of the President, Office of National Drug Control Policy; 2004 Dec.

13. Rice DP. Economic costs of substance abuse, 1995. Proc Assoc Am Physicians. 1999 Feb 1;111(2):119-25.

14. Humensky JL. Are adolescents with high socioeconomic status more likely to engage in alcohol and illicit drug use in early adulthood? Subst Abuse Treat Prev Policy. 2010 Aug 5;5(1):19.

15. Patrick ME, Wightman P, Schoeni RF, Schulenberg JE. Socioeconomic status and substance use among young adults: a comparison across constructs and drugs. J Stud Alcohol Drugs. 2012 Sep; 73(5):772-82.

16. Abel T, Hofmann K, Schori D. Social and regional variations in health status and health behaviours among Swiss young adults. Swiss Med Wkly. 2013;143:w13901.

17. Anthony JC. The epidemiology of drug addiction. Comprehensive handbook of drug and alcohol addiction. 1991:55-86.

18. Braveman P. Health disparities and health equity: concepts and measurement. Annu Rev Public Health. 2006 Apr 21;27:167-94.

19. Diala CC, Muntaner C, Walrath C. Gender, occupational, and socioeconomic correlates of alcohol and drug abuse among US rural, metropolitan, and urban residents. Am J Drug Alcohol Abuse. 2004 Jan $1 ; 30(2): 409-28$.

20. Compton WM, Gfroerer J, Conway KP, Finger MS. Unemployment and substance outcomes in the United States 2002-2010. Drug Alcohol Depend. 2014 Sep 1;142:350-3.

21. Lee JO, Hill KG, Hartigan LA, Boden JM, Guttmannova K, Kosterman R, Bailey JA, Catalano RF. Unemployment and substance use problems among young adults: Does childhood low socioeconomic status exacerbate the effect?. Soc Sci Med. 2015 Oct 31; 143:36-44.

22. Rahimi-Movaghar A, Amin-Esmaeili M, Sharifi V, Hajebi A, Radgoodarzi R, Hefazi M, Motevalian A. Iranian mental health survey: design and field proced. Iran J Psychiatry. 2014;9(2):96-109.

23. Amin-Esmaeili M, Rahimi-Movaghar A, Sharifi V, Hajebi A, Radgoodarzi R, Mojtabai R, Hefazi M, Motevalian A. Epidemiology of illicit drug use disorders in Iran: prevalence, correlates, comorbidity and service utilization results from the Iranian Mental Health Survey. Addiction. 2016 Oct 1;111(10):1836-1847.

24. Vyas S, Kumaranayake L. Constructing socio-economic status indices: how to use principal components analysis. Health Policy Plan. 2006 Nov 1;21(6):459-68.

25. O'donnell O, Van Doorslaer E, Wagstaff A, Lindelow M. Analyzing health equity using household survey data. Washington, DC: World Bank. 2008.

26. Kakwani Nanak C. Income Inequality and Poverty: Methods of Estimation and Policy Applications. Oxford University Press; 1980.

27. Lerman RI, Yitzhaki S. Improving the accuracy of estimates of Gini coefficients. J Econom. 1989 Sep 1;42(1):43-7.

28. Mangalore R, Knapp M, Jenkins R. Income-related inequality in mental health in Britain: the concentration index approach. Psychol Med. 2007 Jul 1;37(07):1037-45.

29. Costa-Font J, Gil J. Would socio-economic inequalities in depression fade away with income transfers? J Happiness Stud. 2008 Dec $1 ; 9(4): 539-58$

30. Patel V, Lund C, Hatherill S, Plagerson S, Corrigall J, Funk M, Flisher AJ. Mental disorders: equity and social determinants. Equity, social determinants and public health programmes. 2010;115.

31. Hong J, Knapp M, McGuire A. Income-related inequalities in the prevalence of depression and suicidal behaviour: a 10-year trend following economic crisis. World Psychiatry. 2011 Feb 1;10(1):40-4.

32. Hanson MD, Chen E. Socioeconomic status and health behaviors in adolescence: a review of the literature. J Behav Med. 2007 Jun 1; 30(3):263.

33. Huckle T, You RQ, Casswell S. Socio-economic status predicts drinking patterns but not alcohol-related consequences independently. Addiction. 2010 Jul 1;105(7):1192-202.

34. Charitonidi E, Studer J, Gaume J, Gmel G, Daeppen JB, Bertholet N.
Socioeconomic status and substance use among Swiss young men: a population-based cross-sectional study. BMC public health. $2016 \mathrm{Apr}$ $14 ; 16(1): 333$.

35. Fothergill KE, Ensminger ME. Childhood and adolescent antecedents of drug and alcohol problems: A longitudinal study. Drug Alcohol Depend. 2006 Mar 15; 82(1):61-76.

36. Karriker-Jaffe KJ. Neighborhood socioeconomic status and substance use by US adults. Drug Alcohol Depend. 2013 Nov 1; 133(1):212-21. 